\title{
Efeito do tempo da aplicação de prostaglandina na resposta folicular em ovelhas durante o ciclo estral ${ }^{1}$
}

\author{
Luis Fernando Uribe-Velásquez ${ }^{2}$, Maria Inês Lenz Souza ${ }^{3}$, Jose Henry Osorio ${ }^{4}$ \\ ${ }^{1}$ Projeto financiado pela FAPESP- SP-Brasil e pela VIP - Universidad de Caldas - Colombia - Convocatoria/2006. \\ 2 Departamento de Saúde Animal, Universidade de Caldas, Manizales, Colômbia. \\ ${ }^{3}$ Departamento de Morfofisiologia, UFMS, Campo Grande, Mato Grosso do Sul, MS, Brasil. \\ ${ }^{4}$ Departamento de Ciências Básicas, Universidade de Caldas, Manizales, Colômbia.
}

RESUMO - Avaliou-se a resposta ovariana, usando ultrassonografia transretal, à aplicação de duas injeções de prostaglandina $\left(\mathrm{PGF}_{2 \alpha}\right)$ em diferentes intervalos. Foram utilizadas 14 fêmeas ovinas da raça Bergamácia durante a estação reprodutiva, sendo que todas receberam uma dose intramuscular de um análogo de $\mathrm{PGF}_{2 \alpha}$. As ovelhas foram distribuídas em dois grupos $(n=7)$. Em um dos grupos, a PGF $2 \alpha$ foi administrada sete dias (PG7) e, no outro, nove dias (PG9) depois da ovulação, quando o folículo dominante da onda 2 encontrava-se nas fases de crescimento e platô, respectivamente. Examinaram-se os ovários diariamente, utilizando-se um ultrassom Aloka 500, provido de um transdutor linear transretal de 7,5 MHz. A ultrassonografia foi iniciada um dia antes da segunda aplicação de prostaglandina até o dia 10 depois da ovulação em ambos os grupos. Amostras de sangue foram colhidas, via punção jugular, a cada dia, para quantificação de progesterona. As concentrações plasmáticas de progesterona mostraram-se menores no PG7 quando comparado com o PG9, imediatamente antes do tratamento com a $\mathrm{PGF}_{2 \alpha}(4,10 \pm 0,17 \mathrm{vs} 4,91 \pm 0,29 \mathrm{ng} / \mathrm{mL}$; respectivamente). A média do diâmetro máximo atingido pelo folículo dominante da onda 2 foi maior no grupo tratado PG7 comparado com o PG9 $(5,5 \pm 0,19$ vs $4,29 \pm 0,26 \mathrm{~mm})$. Houve efeito do dia nos folículos totais. A quantidade de folículos pequenos (2-2,5 mm) foi maior $(4,57 \pm 0,78$ versus $8,42 \pm 1,36)$ no dia 6 , nos grupos PG7 e PG9, respectivamente, mas não foram observadas mudanças nos folículos médios (3-3,5 mm) entre os grupos tratados. A proporção de folículos grandes (4 mm) aumentou depois da luteólise; os valores foram menores nas ovelhas tratadas no PG7 e mantiveram-se estáveis no tempo no PG9. Em ovelhas com rápida e completa luteólise, a ovulação ocorre no folículo dominante da onda 2 em fêmeas tratadas sete ou nove dias após a ovulação.

Palavras-chave: folículo dominante, onda folicular, progesterona $\left(\mathrm{P}_{4}\right)$, sincronização, ultrassonografia

\section{Effect of time of prostaglandin administration on follicular response in ewes during oestrous cycle}

\footnotetext{
ABSTRACT - The purpose of this study was to evaluate ovarian response, using transrectal ultrasonography, to two injections of Prostaglandin $\mathrm{F}_{2 \alpha}\left(\mathrm{PGF}_{2 \alpha}\right)$ given at different intervals. Fourteen Bergamasca ewes were injected with an i.m. dose of $\mathrm{PGF}_{2 \alpha}$ during the breeding season. Ewes were randomly alloted in two groups $(\mathrm{n}=7)$ which received PGF $2 \alpha$ $7 \mathrm{~d}$ (PG7) or $9 \mathrm{~d}$ (PG9) after ovulation (when the dominant follicle of wave 2 was expected to be in the growth and plateau phase, respectively). Ovaries were examined daily with transrectal ultrasonography Aloka 500 with $7.5 \mathrm{MHz}$ linear array transducer. Ultrasonography started 1 day prior to the second PG injection and ended $10 \mathrm{~d}$ after ovulation for both groups. Jugular vein blood samples were collected daily for progesterone assay. Plasma $\mathrm{P}_{4}$ concentration was lower in PG7 than in PG9, immediately before $\mathrm{PGF}_{2 \alpha}$ treatment $(4.10 \pm 0.17$ vs $4.91 \pm 0.29 \mathrm{ng} / \mathrm{mL}$, respectively). Mean maximum diameter size attained by the dominant follicle of wave 2 was larger in the group treated in PG7 when compared with PG9 $(5.5 \pm 0.19$ vs $4.29 \pm 0.26 \mathrm{~mm})$. There was effect of day for total follicles. Number of small follicles $(2-2.5 \mathrm{~mm})$ was greater $(4.57 \pm 0.78$ vs $8.42 \pm 1.36)$ at day 6 , for PG7 and PG9, respectively, whereas no changes were observed in medium follicles (3-3.5 mm) between groups treated. The proportion of large follicles $(4 \mathrm{~mm})$ increased after luteolysis. Values were lower for ewes treated on PG7, whereas values mantained stable over time for ewes treated on PG9. Ewes with rapid and complete luteal regression, ovulation occur from the dominant follicle of wave 2 in females treated on days 7 and 9 .
}

Key Words: dominant follicle, follicular wave, progesterone $\left(\mathrm{P}_{4}\right)$, synchronization, ultrasonography 


\section{Introdução}

Na espécie ovina, o conhecimento dos mecanismos que regulam a dinâmica folicular tem recebido especial atenção, principalmente por duas razões: o interesse do melhoramento da fertilidade, sincronização do estro com maior precisão e aumento da resposta superovulatória mediante administração de gonadotrofinas exógenas; e o fato de a fêmea ovina ser um excelente modelo experimental para o estudo do recrutamento, seleção e dominância folicular, apresentando diversas raças e variedades genéticas com variadas taxas de ovulação e altos índices de prolificidade (Fabre et al., 2006; Liu et al., 2007).

Algumas biotécnicas, como a indução e a sincronização do estro em ovinos e caprinos, vêm sendo bastante utilizadas, por proporcionarem atividade reprodutiva (Safdarian et al., 2006) mesmo durante os períodos de anestro sazonal e lactacional (Amorim et al., 2007; GdeNicolo et al., 2007). Os métodos mais utilizados para a sincronização do estro e estimulação do crescimento folicular em pequenos ruminantes envolvem prostaglandinas (Weems et al., 2006; Uribe-Velásquez et al., 2008a), progesterona e/ou progestágenos e a administração intramuscular de eCG (López-Sebastian et al., 2007; Holtz et al., 2008; UribeVelásquez et al., 2008b).

As prostaglandinas (PG) são uma alternativa para sincronização dos estros, importantes na formulação de sistemas simples e de curta duração. A PG é o fator luteolítico em ruminantes (Goravanahally et al., 2007; Ginther et al., 2009), provocando completa e rápida luteólisis determinando diminuição nas concentrações de progesterona (Shrestha et al., 2010).

A sincronização do estro e ovulação em ovelhas e cabras não depende só do controle na fase luteal, mas também do desenvolvimento ovariano durante a fase folicular (Ali, 2007; Gonzalez-Añover et al., 2007; Menchaca et al., 2007).

Esta pesquisa foi realizada com o objetivo de verificar, pelo acompanhamento ultrassonográfico, o efeito da prostaglandina usada em diferentes intervalos, no crescimento do folículo dominante e na população folicular e, por meio de radioimunoensaio, as concentrações plasmáticas de progesterona $\left(\mathrm{P}_{4}\right)$ em fêmeas ovinas.

\section{Material e Métodos}

O trabalho foi realizado no Departamento de Reprodução Animal e Radiologia Veterinária da Faculdade de Medicina Veterinária e Zootecnia/UNESP - Botucatu, São Paulo, com 14 fêmeas ovinas Bergamácia adultas, previamente examinadas quanto ao estado clínico geral, e comprovadamente aptas, sanitária e reprodutivamente. As ovelhas foram mantidas em boxes de $3 \mathrm{~m} \times 3 \mathrm{~m}$, sob luminosidade natural durante a estação reprodutiva e, duas vezes por dia, expostas a um macho vasectomizado, para observação de estros. A alimentação foi composta de ração concentrada contendo $13,28 \%$ de proteína bruta e 8,99\% de fibra bruta, fornecida na proporção de $1 \mathrm{~kg} /$ animal/dia, e feno de Cynodon dactylon (L.) Pers. cv "Coast Cross", contendo 4,98\% de proteína bruta e 35,88\% de fibra bruta, na matéria seca, fornecido na proporção de $2 \mathrm{~kg} / \mathrm{animal} / \mathrm{dia}$.

As fêmeas foram distribuídas em dois grupos ( $\mathrm{n}=7$ ): no primeiro grupo (PG7) foram administradas, por via intramuscular, duas doses de um análogo de prostaglandina (125 $\mu \mathrm{g}$; Ciosin ${ }^{\mathrm{R}}$, Mallinckrodt Veterinary, São Paulo, Brasil) com um intervalo de sete dias, durante a metade da fase luteal, para sincronização de estro. No segundo grupo (PG9), utilizou-se o intervalo de nove dias para a aplicação das duas doses de $\mathrm{PGF}_{2 \alpha}$. Desde o dia anterior à aplicação da PGF $_{2 \alpha}$ até o dia 10 do ciclo estral, nos dois grupos, as ovelhas, em posição de estação, foram monitoradas via transretal, por meio de ultrassom (SSD-500; Aloka Co. Ltda, Japão), com um transdutor linear prostático humano de 7,5 Mhz (Modelo UST-660-7,5; Aloka Co. Ltda, Japão). As imagens ecográficas foram armazenadas em vídeo (Panasonic NV-SD 425) e diagramas foram desenhados quanto à posição do folículo dominante, permitindo a identificação durante dias sucessivos. O dia da ovulação foi definido como o dia do desaparecimento do maior folículo ( $\geq 5 \mathrm{~mm}$ ). Todos os folículos $\geq 2 \mathrm{~mm}$ foram monitorados e mapeados diariamente. A emergência da nova onda foi definida como de um pool de pequenos folículos com diâmetro médio de 3 a $4 \mathrm{~mm}$, que deram origem a um ou mais folículos com diâmetro maior ou igual a $5 \mathrm{~mm}$. Considerou-se o dia da emergência da onda aquele em que o folículo apresentava $3 \mathrm{~mm}$ de diâmetro, seguido por um aumento em seu diâmetro para valores iguais ou superiores a $4 \mathrm{~mm}$ (Rubianes \& Menchaca, 2003). O diâmetro folicular foi obtido pela média da maior distância (mm) entre dois pontos da cavidade antral dos folículos. A duração do crescimento foi definida como o número de dias entre a primeira mensuração do folículo maior e o dia em que o mesmo cessa seu crescimento progressivo. O dia do diâmetro máximo foi registrado como o maior diâmetro atingido pelo folículo dominante. A taxa de crescimento folicular resultou do diâmetro maior atingido pelo folículo dominante, menos o menor diâmetro detectável pela ultrassonografia, dividido pela duração do crescimento em dias. O número de dias que o folículo dominante mantinha seu diâmetro máximo foi definido como a fase estática. O dia do início da regressão (atresia) foi identificado como o último dia da fase estática 
(platô), a partir do qual o folículo maior iniciou diminuição progressiva em seu diâmetro.

Em todas as ovelhas, pela manhã (8h), colheram-se amostras de sangue, por venopunção jugular, antes da aplicação de $\mathrm{PGF}_{2 \alpha}$, durante todo o período experimental. As amostras de sangue foram colhidas em tubos heparinizados e, imediatamente após, centrifugadas a $2.500 \mathrm{rpm}$ durante 15 minutos, e o plasma armazenado a $-20^{\circ} \mathrm{C}$, para posterior determinação hormonal por radioimunoensaio (RIA). A concentração de $\mathrm{P}_{4}$ foi determinada pela técnica definida por Lafrance \& Goff (1985), com algumas mudanças. Assim, a extração foi trocada pelo danazol (McGinley \& Casey, 1979) e a separação do duplo anticorpo substituída pelo charcol. A sensibilidade do ensaio para $\mathrm{P}_{4}$ foi de $0,1 \mathrm{ng} / \mathrm{mL}$. Analisaram-se todas as amostras num só ensaio, desenvolvido no Centro de Investigação de Reprodução Animal-CRRA, da Université de Montréal, St-Hyacinthé, Québec, Canadá.

Os efeitos das aplicações nas concentrações plasmáticas de $\mathrm{P}_{4}$ foram determinados pela análise de medidas repetidas utilizando-se o programa Statistical Analysis System (Latour \& Littell, SAS Institute Inc, 1996). Para os efeitos fixos (tratamento, dia, tratamento $\times$ dia) utilizou-se o teste $\mathrm{F}$ e, para as comparações múltiplas das médias, o teste de tukey-kramer. O teste não-paramétrico de Wilcoxon-Mann-Whitney foi utilizado para as variáveis do folículo dominante durante as ondas foliculares: 1) dia de emergência; 2) dia do diâmetro máximo; 3) diâmetro máximo; 4) dias na fase estática; e 5) dia de regressão, bem como para analisar a população dos folículos grandes. Para a análise da taxa de crescimento, utilizou-se ANOVA e as médias foram comparadas pelo teste $\mathrm{F}$. Os folículos foram classificados em pequenos (2-2,5 mm), médios (3-3,5 mm) e grandes (>4 mm). As médias da população dos folículos pequenos e médios foram transformadas $\left(\log _{10}\right)$ para diminuir a variabilidade dos dados, antes de serem submetidas à ANOVA e, as médias, comparadas pelo teste F.

\section{Resultados e Discussão}

Todas as fêmeas ovinas dos grupos experimentais manifestaram estro dentro das 72 horas depois das aplicações, sem apresentar diferença ( $\mathrm{P}>0,05)$, corroborando os achados de Kridli e Al-Khetib (2006) e Uribe-Velásquez et al. (2008a). O estágio da fase luteal provocou mudanças na resposta das ovelhas na indução da luteólise, usando prostaglandinas exógenas. Nenhum dos fatores, como localização dos ovários, condição corporal ou peso vivo, afetou o monitoramento dos ovários na avaliação ultrassonográfica.

Segundo Menchaca et al. (2004), protocolos usando o intervalo de sete dias para a administração de prostaglandina apresentaram alta eficiência na sincronização do estro. Assim, ovelhas multíparas responderam nas primeiras 72 horas (94\%) depois do tratamento, enquanto, nas ovelhas nulíparas, a resposta foi menor (82\%). Além disso, o início do estro apresentou-se numa faixa estreita, com $80 \%$ das ovelhas demonstrando estro nas 25 e 48 horas depois da segunda dose de prostaglandina. Pode-se concluir, então, que, com o uso do intervalo curto de sete dias na sincronização de estro, as ovelhas estarão bem mais sensitivas à dose luteolítica da prostaglandina. Pesquisas desenvolvidas em fêmeas leiteiras (Répási et al., 2005) utilizando também duas doses de PG (cloprostenol ou dinoprost) em intervalo de 8 horas, resultou numa maior percentagem de animais apresentando estro nos cinco dias após da aplicação e uma significativa taxa de prenhes quando comparado com as fêmeas submetidas só a uma aplicação.

O dia de emergência da primeira onda folicular não diferiu entre os dois grupos experimentais: foi de $-0,71 \pm 0,29$ e $0,57 \pm 0,53$ para os grupos tratados com $\mathrm{PGF}_{2 \alpha}$ nos intervalos de sete (PG7) e nove dias (PG9), respectivamente (Tabela 1), valores próximos aos obtidos por UribeVelásquez et al. (2002, 2008c, 2010) e menores que os descritos por Toosi et al. (2010).

O folículo dominante atingiu seu diâmetro máximo de $5,5 \pm 0,19 \mathrm{~mm}$ no dia $5,43 \pm 0,37$ nos animais submetidos ao intervalo PG7 e 4,29 $\pm 0,26 \mathrm{~mm}$ no dia $4,57 \pm 0,43$ nos animais submetidos ao intervalo PG9, sendo estatisticamente significativo só para diâmetro do folículo $(\mathrm{P}<0,05)$. O diâmetro máximo atingido pelos animais na aplicação de prostaglandina com o intervalo de sete dias está de acordo com os valores observados por Uribe-Velásquez et al. (2008c).

Os dias do platô dos animais submetidos aos intervalos de PG7 e PG9 não apresentaram diferença significativa, com resultados similares aos demonstrados por UribeVelásquez et al. (2002).

Tabela 1 - Folículo dominante da primeira onda folicular em fêmeas ovinas Bergamácia sincronizadas com $\mathrm{PGF}_{2 \alpha}$ utilizando diferentes intervalos de aplicação (PG7 dias vs PG9 dias)

\begin{tabular}{lrr}
\hline Variável & PG7 dias & PG9 dias \\
\hline Dia de emergência & $-0,71 \pm 0,29 \mathrm{a}$ & $0,57 \pm 0,53 \mathrm{a}$ \\
Dia do máximo diâmetro & $5,43 \pm 0,37 \mathrm{a}$ & $4,57 \pm 0,43 \mathrm{a}$ \\
Diâmetro máximo (mm) & $5,5 \pm 0,19 \mathrm{a}$ & $4,29 \pm 0,26 \mathrm{~b}$ \\
Dias do platô & $1,86 \pm 0,26 \mathrm{a}$ & $1,29 \pm 0,18 \mathrm{a}$ \\
Taxa de crescimento $(\mathrm{mm} / \mathrm{dia})$ & $0,91 \pm 0,55 \mathrm{a}$ & $1,0 \pm 0,09 \mathrm{a}$ \\
\hline Letras diferentes nas linhas apresentam diferenças estatisticamente significativas \\
a versus b $(\mathrm{P}<0,05)$.
\end{tabular}

R. Bras. Zootec., v.40, n.5, p.985-991, 2011 
Estudos prévios têm mostrado que a dominância é efetiva somente nos primeiros dias do ciclo estral e bem mais pronunciada no final do crescimento do folículo ovulatório (Gonzalez-Bulnes et al., 2005). Nesta pesquisa, a taxa de crescimento não diferiu entre os grupos tratados, comvalores de 0,91 $\pm 0,55$ e 1,0 $\pm 0,09 \mathrm{~mm} /$ dia, respectivamente, para as fêmeas tratadas no sétimo e nono dias. Os valores observados para a taxa de crescimento estão de acordo com os resultados obtidos no trabalho de Toosi et al. (2010) em ovelhas (0,9 a 1,3 mm/dia). Martínez-García et al. (2007) sugeriram que o aumento na taxa de crescimento em alguns folículos acontece depois da diminuição nas concentrações de progesterona no sangue.

De acordo com as observações do experimento, fica evidente que o crescimento folicular é um processo contínuo e o padrão de crescimento folicular em ondas faz com que a população de folículos de diversas classes de tamanhos altere-se ao longo do ciclo (Seekallu et al., 2009; 2010). Assim, o folículo pré-ovulatório presente nos dias sete ou nove após o estro deve-se achar em fase de crescimento. No entanto, o status hormonal dos folículos grandes não foi determinado. Do mesmo modo, alguns dos folículos grandes presentes nos dias 11 e 16 podem encontrar-se em fase de crescimento, mas existe a possibilidade de estarem em fase estática ou de regressão (Gonzalez-Bulnes et al., 2005). A quantidade de ondas de crescimento folicular e o dia de emergência folicular são muito variáveis entre animais (Uribe-Velásquez et al., 2008b). A referida variabilidade provoca uma perda da sincronização da segunda e das seguintes ondas foliculares. A indução da luteólise em animais nos quais o folículo maior encontra-se na fase estática ou atrésica pode provocar atraso na seleção e no crescimento do folículo ovulatório (Gonzalez-Bulnes et al., 2005).

Os resultados obtidos nesta pesquisa comprovaram que os folículos ovulatórios foram originados dos folículos antrais presentes no ovário no momento da aplicação do cloprostenol, independentemente do dia do tratamento. Em todas as fêmeas ovinas, observou-se pelo menos um corpo lúteo na metade da fase luteal, o qual sofreu luteólise em resposta à dosagem luteolítica do análogo de prostaglandina (cloprostenol), em todos os animais, fato constatado pela técnica ultrassonográfica e pelo marcante declínio nas concentrações plasmáticas de progesterona $\left(\mathrm{P}_{4}\right)$, indicando esta regressão do corpo lúteo. O dia da ovulação foi definido como dia zero (0 = dia da ovulação).

A distribuição (médias $\pm \mathrm{EP}$ ) dos folículos pequenos (2-2,5 mm), médios (3-3,5 mm) e grandes (> $4 \mathrm{~mm})$ nas fêmeas dos dois grupos estudados (PG7 vs PG9), é apresentada, respectivamente, na Figura 1a,b,c.

Durante o início e a metade da fase luteal, observou-se, em todos os dias, crescimento dos folículos pequenos (Figura 1,a), concordando com as observações de Uribe-Velásquez et al. (2008b) em ovelhas Bergamácia. Neste protocolo, constatou-se que o recrutamento dos folículos destinados a ovular foi realizado a partir dos folículos > $2 \mathrm{~mm}$ no momento da luteólise. A quantidade de folículos pequenos foi significativa nos dias -1 préovulatório e no dia 6 pós ovulação, sendo maior para as fêmeas tratadas com a $\mathrm{PGF}_{2 \alpha}$ no nono dia quando comparadas com as fêmeas tratadas no sétimo dia, com valores no dia -1 de $8,43 \pm 0,97$ vs $5,14 \pm 0,70(P<0,05)$, e no dia 6 de $8,43 \pm 1,36$ vs $4,57 \pm 0,78(\mathrm{P}<0,05)$, respectivamente.

A quantidade média dos folículos médios (Figura 1b) não apresentou diferença estatística significativa entre os dois grupos de animais estudados. Possivelmente, a maior quantidade de folículos médios pós-ovulação pode ser atribuída ao maior pool de folículos pré-ovulatórios presentes nos dias -2 e -1 (Uribe-Velásquez et al., 2002) e pode ter sido também um indicador da prevenção do processo normal de atresia folicular.

O crescimento de folículos pré-ovulatórios durante a fase folicular, em resposta à administração de prostaglandina, inibiu o desenvolvimento de folículos presentes dependentes de gonadotrofinas (3-3,5 mm), de forma semelhante a outras pesquisas prévias (Gonzalez-Bulnes et al., 2005; GonzalezAñover et al., 2007; Uribe-Velásquez et al., 2008b).

A aplicação da $\mathrm{PGF}_{2 \alpha}$ no sétimo dia após a ovulação aumentou $(\mathrm{P}<0,05)$ o número de folículos grandes nos dias $3(1,0 \pm 0,22$ vs $0,29 \pm 0,18), 4(1,71 \pm 0,29$ vs $1,29 \pm 0,18)$, $6(1,15 \pm 0,20$ vs $0,14 \pm 0,14)$ e $8(1,14 \pm 0,26$ vs $0,29 \pm 0,18)$, respectivamente, para as fêmeas ovinas tratadas nos dias sétimo e nono pós ovulação (Figura 1c).

Neste estudo, as fêmeas ovinas mostraram uma distribuição e tamanho dos folículos grandes semelhante ao processo durante o estro natural. Alguns folículos grandes não exercem dominância, portanto, são incapazes de ovular, mas alguns deles ovulam normalmente.

A sincronização utilizada não influenciou significativamente a quantidade média da população folicular total, no início e metade da fase luteal do ciclo estral, entretanto houve diferença $(\mathrm{P}<0,05)$ entre os dias experimentais, sendo que também foi constatada diferença significativa na interação aplicação × dia $(\mathrm{P}<0,05)$.

Dos resultados obtidos, é razoável levantar a hipótese de que as taxas de baixa fertilidade reportadas, ao usar-se prostaglandina, podem ser mais relacionadas ao momento do tratamento (Kusina et al., 2000). Desse modo, a 
administração de prostaglandina na metade da fase luteal (prática usual com a presença de um corpo lúteo ativo respondendo ao tratamento) comprovou ser compatível com folículos grandes exercendo a dominância (Fernandez-Moro et al., 2008). A melhor resposta ovariana pode-se esperar quando as fêmeas são tratadas no início e final da fase luteal. Assim, o início rápido do estro e grande quantidade de animais ovulando são esperados quando as fêmeas são tratadas ao início da fase luteal (González-Bulnes et al., 2005). Em fêmeas ovinas é conhecido que as doses de prostaglandina são efetivas desde o terceiro dia depois da ovulação (Ali et al., 2009). Assim, duas doses de prostaglandina com um intervalo de sete dias são eficientes para induzir a sincronização do estro e da ovulação (Menchaca et al., 2004).

Houve diferença significativa $(\mathrm{P}<0,0001)$ nas concentrações plasmáticas de $\mathrm{P}_{4}$ entre os grupos durante a fase em estudo (Figura 2). Do mesmo modo, constatou-se também diferença nos dias $(\mathrm{P}<0,0001)$ e na interação aplicação e dia $(\mathrm{P}<0,0001)$. As concentrações de $\mathrm{P}_{4}$ no plasma, não foram diferentes entre os grupos tratados no sétimo e nono dias mostrando, nos dias -2 e -1 antes da
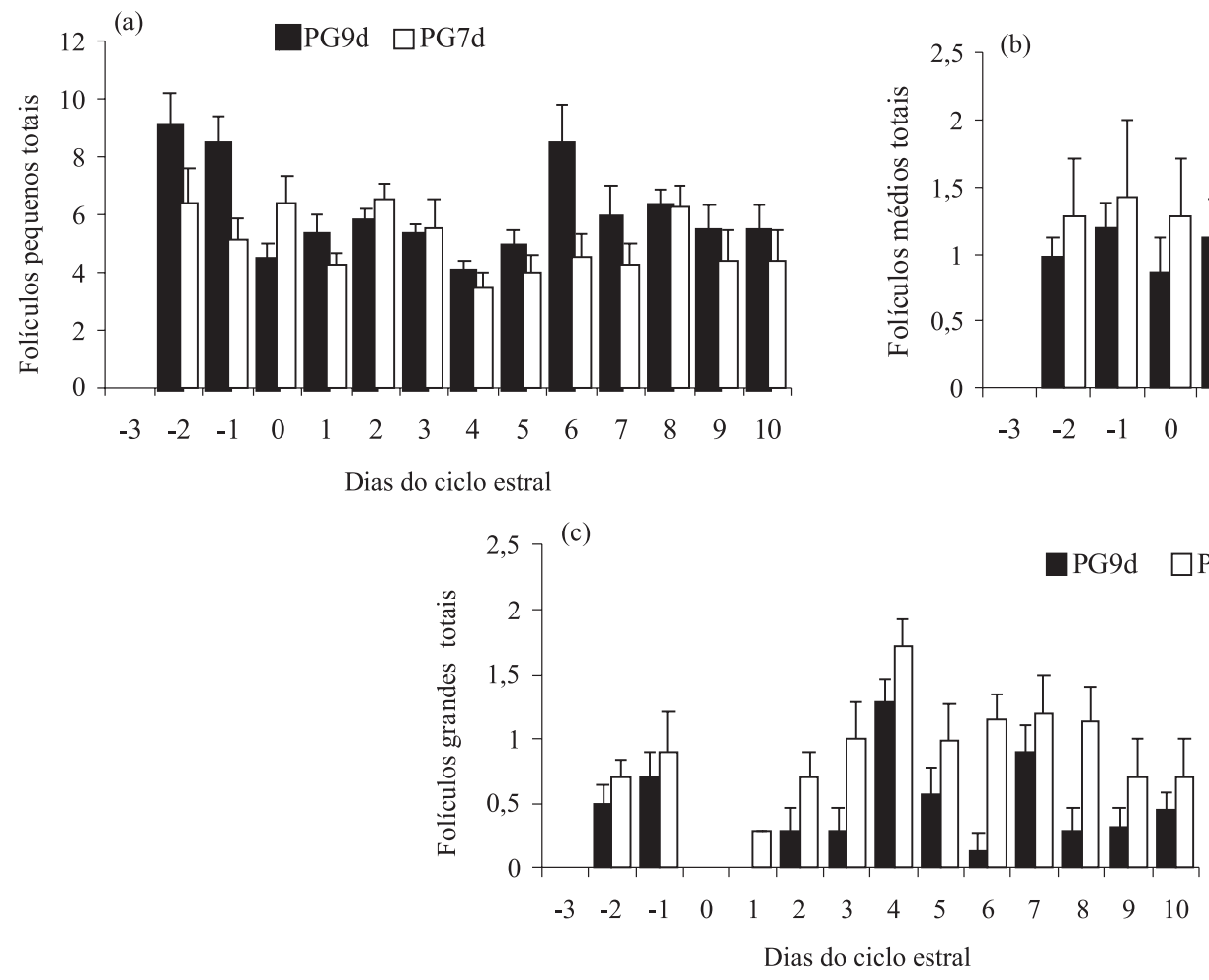

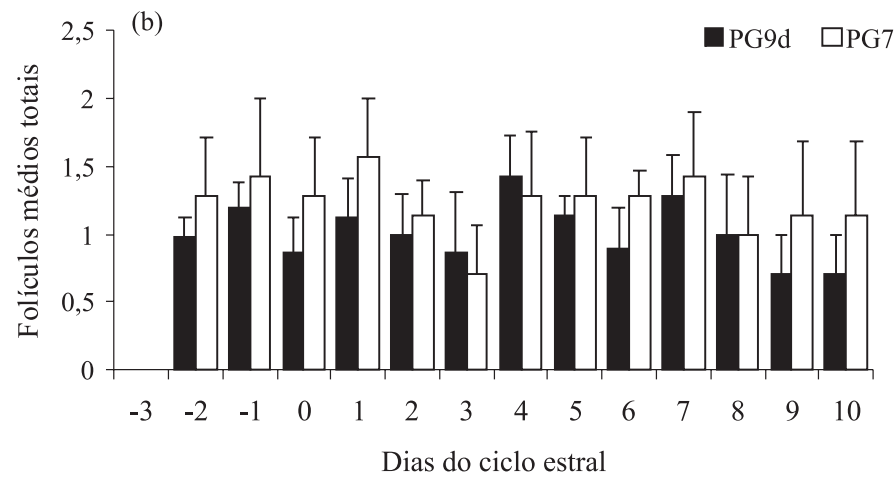

Dias do ciclo estral 
ovulação, valores médios de $0,32 \pm 0,17$ vs $0,24 \pm 0,17 \mathrm{ng} / \mathrm{mL}$; e 0,30 0,33 vs $0,27 \pm 0,17 \mathrm{ng} / \mathrm{mL}$, respectivamente, de forma semelhante aos achados de Uribe-Velásquez et al. (2008 a,b,c), os quais também observaram valores abaixo de $1 \mathrm{ng} / \mathrm{mL}$ ao longo da fase folicular até a ovulação, dois a três dias mais tarde.

As concentrações de $\mathrm{P}_{4}$ no plasma variaram significativamente $(\mathrm{P}<0,0001)$ entre os grupos tratados a partir do terceiro dia até o décimo dia após a ovulação, apresentando as maiores concentrações no grupo tratado com intervalo de sete dias. O aumento nas concentrações plasmáticas de $\mathrm{P}_{4}$ após o terceiro dia do ciclo estral, no grupo tratado com intervalo de sete dias, pode ser o resultado da atividade do corpo lúteo somado à atividade de folículos grandes luteinizados.

\section{Conclusões}

A dinâmica folicular altera-se com a aplicação de prostaglandina, porém de forma não muito distinta daquela do processo normal de regressão luteal ao final do ciclo estral. Além disso, em fêmeas ovinas com completa e rápida luteólise, tratadas nos dias 7 e 9, a ovulação acontece no folículo dominante da segunda onda folicular. A indução da luteólise com prostaglandina durante o ciclo estral pode ser uma eficiente ferramenta em protocolos de reprodução assistida em fêmeas ovinas.

\section{Referências}

ALI, A. Effect of time of eCG administration on follicular response and reproductive performance of FGA-treated Ossimi ewes. Small Ruminant Research, v.72, p.33-37, 2007.

ALI, A.; HAYDER, M.; SAIFELNASER, E.O.H. Ultrasonographic and endocrine evaluation of three regimes for oestrus and ovulation synchronization for sheep in the subtropics. Reproduction Domestic Animal, v.44, p.873-878, 2009.

AMORIM, E.A.M.; TORRES, C.A.A.; AMORIM, L.S. et al. Dinâmica follicular em cabras da raca Toggenburg em lactação tratadas ou não com somatotropina bovina recombinante. Arquivos Brasileiros de Medicina Veterinária e Zootecnia, v.59, p.1500-1508, 2007.

FABRE, S.; PIERRE, A.; MULSANT, P. et al. Regulation of ovulation rate in mammals: contribution of sheep genetic models. Reproductive Biology and Endocrinology, v.4, p.1-12, 2006.

FERNANDEZ-MORO, D.; VEIGA-LOPEZ, A.; ARIZNAVARRETA, J.A.F. et al. Preovulatory follicle development in goats following oestrous synchronization with progestagens or prostaglandins. Reproduction in Domestic Animals, v.43, p.9-14, 2008.

GdeNICOLO, S.T.; MORRIS, S.T.; KENYON, P.R. et al. Induced seasonal reproductive performance in two breeds of sheep. Animal Reproduction Science, v.103, p.278-289, 2007.

GINTHER, O.J.; ARAUJO, R.R.; PALHAO, M.P. et al. Necessity of sequencial pulses of prostaglandin $F_{2 a l p h a}$ for complete physiologic luteolysis in cattle. Biology of Reprouction, v.80, p.641-648, 2009.
GONZÁLEZ-BULNES, A.; VEIGA-LÓPEZ, A.; GARCIA, P. et al. Effects of progestagens and prostaglandin analogues on ovarían function and embryo viability in sheep. Theriogenology, v.63, p.2523-2534, 2005.

GONZALEZ-AÑOVER, P.; ENCINAS, T.; VEIGA-LOPEZ, A. et al. Effects of breed on folicular dynamics and oestradiol secretion during the folicular phase in sheep. Reproduction Domestic Animal, v.42, p.29-33, 2007.

GORAVANAHALLY, M.P.; SEN, A.; INSKEEP, E.K. et al. PKCepsilon and an increase in intracellular calcium concentration are necessary for $\mathrm{PGF}_{2 \text { alpha }}$ to inhibit $\mathrm{LH}$-stimulated progesterone secretion in cultured bovine steroidogenic luteal cells. Reproductive Biology and Endocrinology, v.5, p.1-13, 2007.

HOLTZ, W.; SOHNREY, B.; GERLAND, M. et al. Ovsynch synchronization and fixed-time insemination in goats. Theriogenology, v.69, p.785-792, 2008.

KRIDLI, R.T.; AL-KHETLIB, S.S. Reproductive responses in ewes treated with eCG or increasing doses of royal jelly. Animal Reproduction Science, v.92, p.75-85, 2006.

KUSINA, N.T.; TARWIREI, H.; HAMUDIKUWANDA, H. et al. A comparison of the effects of progesterone sponges and ear implants, $\mathrm{PGF}_{2 \alpha}$ and their combination on efficacy of estrus synchronization and fertility of Mashona goats does. Theriogenology, v.53, p.1567-1580, 2000.

LAFRANCE, M.; GOFF, A.K. Effect of pregnancy on oxytocininduced release of prostaglandin $\mathrm{F}_{2 \alpha}$ in heifers. Biology of Reproduction, v.3, p.1113-1119, 1985.

LATOUR, D.; LITTELL, R. Advanced general linear models with an emphasis on mixed models. Version 6.12. Cary: SAS Institute, 1996. 268p.

LIU, X.; DAI, Q.; HART, E.J. et al. Ultrasonographic characteristics of ovulatory follicles and associated endocrine changes in cyclic ewes treated with medroxyprogesterone acetate (MAP)-releasing intravaginal sponges and equine chorionic gonadotrophin (eCG). Reproduction Domestic Animals, v.42, p.393-401, 2007.

LÓPEZ-SEBASTIAN, A.; GONZÁLEZ-BULNES, A.; CARRIZOSA, J.A. et al. New estrus synchronization and artificial insemination protocol for goats based on male exposure, progesterone and cloprostenol during the non-breeding season. Theriogenology, v.68, p.1081-1087, 2007

MARTÍNEZ-GARCÍA, J.A.; SÁNCHEZ-TORRES, M.T.; CORDERO, J.L. et al. Ovarian follicular dynamics after cauterization of the dominant follicle in anoestrous ewes. Animal Reproduction Science, v.98, p.225-232, 2007.

McGINLEY, R.; CASEY, J.H. Analysis of progesterone in unextrated serum; a method using danazol (17 a-preg-4-en20-yno $(2,3)$ isoxasol-17-ol) a bloker of steroid binding to proteins. Steroids, v.33, p.127-138, 1979.

MENCHACA, A.; MILLER, V.; GIL, J. et al. Prostaglandin $\mathrm{F}_{20}$ treatment associated with timed artificial insemination in ewes. Reproduction in Domestic Animals, v.39, p.1-4, 2004.

MENCHACA, A.; MILLER, V.; SALVERAGLIO, V. et al. Endocrine, luteal and folicular responses after the use of the short-term protocol to synchronize ovulation in goats. Animal Reproduction Science, v.102, p.76-87, 2007.

RÉPÁSI, A.; BECKERS, J.F.; SULON, J. et al. Effect of the type and number of prostaglandin treatment on corpum luteum, the largest follicle and progesterone concentration in dairy cows. Reproduction in Domestic Animals, v.40, p.436-442, 2005.

RUBIANES, E.; MENCHACA, A. The pattern and manipulation of ovarian follicular growth in goats. Animal Reproduction Science, v.78, p.271-287, 2003.

SAFDARIAN, M.; KAFI, M.; HASHEMI, M. Reproductive performance of Karakul ewes following different oestrous synchronization treatments outside the natural breeding season. South African Journal of Animal Sciences, v.36, p.229-234, 2006. 
SEEKALLU, S.V.; TOOSI, B.M.; RAWLINGS, N.C. LH pulse frequency and the emergence and growth of ovarian antral follicular waves in the ewe during luteal phase of the estrous cycle. Reproductive Biology and Endocrinology, v.7, p.1-16, 2009.

SEEKALLU, S.V.; TOSSI, B.M.; ZIEGLER, A. et al. Pulsed GnRH secretion and the FSH secretory peaks that initiate ovarian antral follicular wave emergence in anestrous ewes. Animal Reproduction Science, v.120, p.56-64, 2010.

SHRESTHA, H.K.; BEG, M.A.; SIDDIQUI, M.A.R. et al. Dynamic progesterone responses to stimulation of a natural pulse of a metabolite of prostaglandin $\mathrm{F}_{2 \alpha}$ in heifers. Animal Reproduction Science, v.118, p.118-123, 2010.

TOOSI, B.M.; SEEKALLU, S.V.; BARRET, D.M.W. et al. Characteristics of peak in serum concentrations of folliclestimulating hormone and estradiol, and follicular wave dynamics during the interovulatory interval in cyclic ewes. Theriogenology, v.73, p.1192-1201, 2010.

URIBE-VELÁSQUEZ, L.F.; OBA, E.; LARA-HERRERA, L.C. et al. Respostas endócrinas e ovarianas associadas com o folículo dominante da primeira onda folicular em ovelhas sincronizadas com CIDR ou PGF $2 \alpha$. Revista Brasileira de Zootecnia, v.31, p.944-953, 2002.

URIBE-VELÁSQUEZ, L.F.; SOUZA, M.I.L.; LOAIZA, A.M.E. Efecto de la sincronización del estro con prostaglandina- $\mathrm{f}_{2 \alpha}$ vs CIDR + 500 UI de eCG en ovejas Bergamacia durante el inicio de la fase luteal. Revista Científica, v.18, p.368-373, 2008a.

URIBE-VELÁSQUEZ, L.F.; OBA, E.; SOUZA, M.I.L. Población folicular y concentraciones plasmáticas de progesterona $\left(\mathrm{P}_{4}\right)$ en ovejas sometidas a diferentes protocolos de sincronización. Archivos de Medicina Veterinaria, v.40, p.83-88, 2008 b. URIBE-VELÁSQUEZ, L.F.; OBA, E.; SOUZA, M.I.L. Efeitos da progesterona exógena sobre o desenvolvimento folicular em ovelhas. Arquivos Brasileiros de Medicina Veterinária e Zootecnia, v.60, p.58-65, 2008c.

URIBE-VELÁSQUEZ, L.F.; SOUZA, M.I.L.; OSORIO, J.H. Resposta ovariana de cabras submetidas a implantes de progesterona seguidos de aplicações de gonadotrofina coriônica eqüina. Revista Brasileira de Zootecnia, v.39, p.1214-1222, 2010.

WEEMS, C.W.; WEEMS, Y.S.; RANDEL, R.D. Prostaglandins and reproduction in female farm animals. The Veterinary Journal, v.171, p.206-228, 2006. 